\title{
Surgical Treatment of Colorectal Cancer Metastases
}

\author{
Velimir Škrbić, ${ }^{1,2}$ Milan Simatović, ${ }^{1,2}$ Goran Janjić, ${ }^{1}$ Dalibor Šaran ${ }^{1}$
}

\section{Abstract}

Background/Aim: Colorectal metastatic liver tumours are the most common secondary liver tumours. During the life of patients with colorectal tumorous, this liver metastases will develop either synchronously or metachronously in half of the patients. Approximately $25 \%$ of patients with colorectal cancer diagnosis have secondary deposits in the liver and the additional $25 \%$ of patients will develop metastases within five years. The objective was to investigate whether anatomic resections of the liver present a method of choice in surgical treatment of colorectal liver metastases compared to metastasectomy surgery.

Methods: A total of 65 patients were divided into two groups. Patients in the first group underwent metastasectomies consisting in the removal of metastases and the surrounding liver parenchyma no more than $1 \mathrm{~cm}$ by Kelly clamp crushing technique or LigaSure vessel-sealing system. Patients in the second group were subjected to the anatomic resection of the liver where not only metastases were removed, but also the associated anatomical segment or section or half the liver, depending on the number and localisation of metastases.

Results: The mean values ( \pm standard deviation) of the overall survival for the first and the second group were $36 \pm 4.8$ months and $36 \pm 2.6$ months, respectively. The mean values ( \pm standard deviation) of the disease-free survival in the first and in the second group were $18 \pm 2.22$ months and $22 \pm 0.74$ months, respectively. None of the found inter-group differences were statistically significant.

Conclusion: It can be concluded that metastatic surgery for colorectal liver metastases and anatomic resections have almost the same results and are irreplaceable methods in the treatment of colorectal liver metastases.

Key words: colorectal cancer, liver, metastasis, metastasectomy, anatomical resection.
(1) University Clinical Centre of the Republic of Srpska, Banja Luka, the Republic of Srpska, Bosnia and Herzegovina.

(2) Faculty of Medicine, University of Banja Luka, Banja Luka, the Republic of Srpska, Bosnia and Herzegovina.
Correspondence:

VELIMIR ŠKRBIĆ

E: velimirskrbic01@gmail.com

\section{ARTICLE INFO}

Received: 14 May 2020 Revision received: 28 April 2020 Accepted: 1 June 2020

\section{Introduction}

Colorectal cancer is the most common gastrointestinal malignant tumour that gives rise to metastatic liver tumours. ${ }^{1}$ Approximately $25 \%$ of patients with colorectal cancer at time of diagnosis have presence of secondary liver metastases and in 25 $\%$ of patients metastases are generated within the next five years. ${ }^{2}$ The first liver resection for colorectal liver metastases was performed by Catell in 1940. By improvement of surgical techniques, by introducing of new cytostatic drugs and by reducing the resection margin to less than $1 \mathrm{~cm}$, the application of interventional radiology, portal venous embolisation allowed more patients in the unresectable group to move to the resectable tumour group. The goal of treatment is surgical removal of all metastatic tumours in the liver, because, based on the experience, 25-60\% of the operated patients survive for five years. ${ }^{2}$ Seventy percent of the conservatively treated patients with metastases in the liver do not survive even a year. ${ }^{3}$ 
Metastasectomies belong to the group of nonanatomic resection surgeries where the excision of the hepatic parenchyma within $0.5-1 \mathrm{~cm}$ of the metastases is performed according to Kelly clamp crushing technique ${ }^{4}$ or LigaSure vessel-sealing system..$^{5}$ Anatomical liver resections are based on the principles of segmental and sector anatomy of the liver. The extent of anatomical surgery goes from segmentecomies, bisegmentectomies, sectionectomies and hemihepatectomies.

The aim of this study was to investigate whether anatomic resection of the liver is the method of choice in surgical treatment of colorectal liver metastases compared to metastasectomy surgery.

\section{Methods}

The survey was conducted at the University Clinical Centre of Banja Luka. The study covered the period from January 2007 to January 2014. The study was conducted in 70 patients divided into two groups (group A and B). Criteria for inclusion in the study were patients who were technically able to be operated by either a surgical method of metastasectomy or by a method of anatomical resections. Metastatic disease had to be localised only in the liver.

The first group of patients $\mathrm{N}=35$ (group A) underwent surgical metastasectomies of the tumour and the second group of $\mathrm{N}=30$ (group B) underwent anatomical resection of the tumour. In group A metastasectomy consisted in removing metastases and surrounding liver parenchyma no more than $1 \mathrm{~cm}$ from the metastasis by the Kelly clamp crushing technique or the LigaSure vessel sealing system. The patients in group B underwent the anatomical resection of liver metastases that consisted of the removal of metastases in the corresponding anatomical segment or section of half of a liver depending on the number and position of metastases.

The following surgical approaches were used: medial, J incision and Makuch laparotomy. After opening, mobilisation of the liver was performed, followed by the intraoperative ultrasonography (IOUSA), which provided the precise tumour position. Liver resection was performed at reduced central venous pressure (CVP) of $0-5 \mathrm{~cm} \mathrm{H}_{2} \mathrm{O}$ ) and with the patient being in the Trendelenburg position. Parenchymal transection begun with diathermy tag of the resection line; the section parenchyma was performed by LigaSure or Kelly clamp crushing technique. Biliovascular structures were secured with clips and vascular sutures.

\section{Results}

Patients in group A who underwent metastatectomy had mean overall survival based on Kaplan-Meier curves $36 \pm 4.8$ months and a one-year, two-year and three-year survival was $85.3 \%, 68.3$ $\%$ and $50 \%$ (Figure 1).

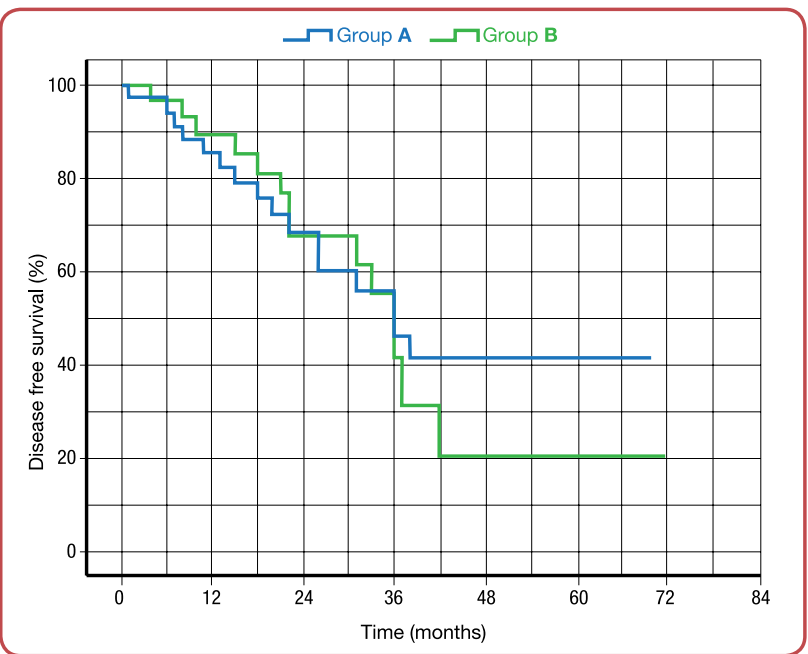

Figure 1. Mean overall survival in patients with colorectal carcinoma with liver metastases treated by metastasectomy (Group A) or with anatomical resection of the liver (Group B)

The mean overall of survival in patients of Group B who had anatomical hepatic surgery was $36 \pm$ 2.6 months and the one-year, two-year and threeyear survival was $89.3 \%, 67.5 \%$ and $50 \%$, respectively.

After the statistical comparisons of Kaplan Meier curves of overall survival by Mantel-Cox test $\left(\chi^{2}=\right.$ $0.167 ; p=0.683$ ), it can be concluded that there was no significant difference between the study groups $A$ and $B$ when it comes to overall survival ( $p>0.05)$.

The mean value of disease-free survival in group A was $18 \pm 2.22$ months, with the one-year, twoyear and three-year disease-free survival $64.7 \%$, $29.1 \%$ and $29.1 \%$, respectively.

In group B, the value if disease-free survival was 


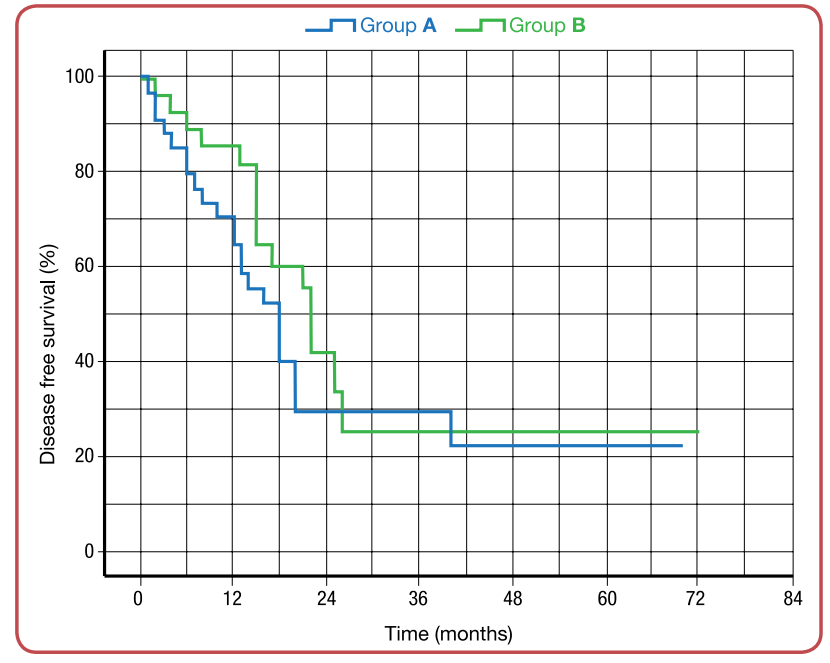

Figure 2. Mean disease-free survival in patients with colorectal carcinoma with liver metastases treated by metastasectomy (Group A) or with anatomical resection of the liver (Group B).

$22 \pm 0.74$ months, with one-year, two-year and three-year disease-free survival percentage of $85.7 \%, 41.6 \%$ and $25 \%$, respectively (Figure 2).

After the statistical comparisons of Kaplan Meier disease-free survival curves performed with Mantel-Cox test $\left(\chi^{2}=1.357 ; \mathrm{p}=0.244\right)$, it can be concluded that there was no statistically significant difference $(p>0.05)$ between the study groups $A$ and $\mathrm{B}$ when it comes to disease-free survival.

\section{Discussion}

In a study published by Scheele and his associates, 902 patients with metastatic colorectal liver cancer without resection were monitored and only 21 patients or $2.3 \%$ survived for three years, while there was no record of five-year survival. ${ }^{3}$

In the study published by Fong and his associates in 1,001 patients who underwent surgical removal of metastatic colorectal cancer in the liver five-year survival of $37 \%$ and an average life expectancy of 42 months were found. ${ }^{6}$ In this study, two basic surgical treatment methods of metastases in the liver were compared and the following results were found: mean survivals in anatomic and metastasectomic surgery were 39 and 46 months, respectively. 6 While the one-, three- and five-year survival rates for anatomical surgery was $85 \%, 53 \%$ and $37 \%$, respectively, 6 in the present study the results for the anatomical surgery were similar - $89.3 \%$ after one-year and $50 \%$ after three years.
According to the Fong et al study, ${ }^{6}$ the data for metastasectomic surgery for survival after one, two and three years amounted $93 \%, 75 \%$ and $40 \%$, respectively, while in the present study the patients that underwent metastasectomy had one- and three-year survival rates of $85.6 \%$ and $50 \%$, respectively.

DeMatteo and associates monitored 267 patients operated in the period from 1985 to 1998. Among 119 patients operated by metastasectomic surgery and 148 patients operated anatomically, mean overall survival was 53 months in the anatomical surgery versus 38 months for metastasectomic surgery. ${ }^{7}$ In the present study that included 65 patients, ie 35 metastasectomic surgeries and 30 anatomical surgeries, overall survival was 36 months for both types of surgeries. When data for one-, two- and three-year survivals in the anatomical surgeries and in metastatesectomic surgery were $89 \%, 67 \%, 50 \%$ and $85 \%, 68 \%, 50 \%$, respectively, without any significant difference.

Scheele in the study in 436 surgically treated patients for liver metastases of colorectal cancer states after five-year a disease-free interval was reached in $33.6 \%$ patients. ${ }^{3}$ In the present study that includes 65 patients, mean disease-free interval was 22 months for anatomical surgery and 18 months for metastasectomic surgeries.

These percentages of 5-year overal survival associated with careful selection and operating techniques are in accordance with the general trend of increasing the overall survival from early $5 \%$ to $40-50 \%$ nowadays. ${ }^{8}$ One of the important factors affecting the overall survival in these patients is the type of the metastasectomy - the R0 type (excision of the tumour with a 1-cmbreadth of normal surrounding liver tissue), like the one in the present study - assures more favourable outcomes than the R1 or R2 type. In the clinical study by Allard et $\mathrm{al}^{9}$ the 3- and 5-year overall survival in patients undergoing R0/R1 liver colorectal metastasectomy was $61 \%$ and $39 \%$ and in those ones that had R2 resection or no metastasectomy at all it was $29 \%$ and $5 \%$, respectively.

Some surgeons proposed the so-called liver-first approach for treatment of the liver colorectal metastases, which means that the patient with colorectal cancer and liver metastases should first receive pre-operative chemotherapy, then have their liver metastases removed and finally 
undergo the colorectal surgery aimed at resection of the primary tumour. In a systematic review by Lam and co-workers ${ }^{10}$ it was shown that the median overall survival in these patients was 40 (range 19-50) months, with a recurrence rate of $52 \%$. However, a meta-analysis by Kelly et $\mathrm{al}^{11}$ that included 18 studies and 3,605 patients found no significant difference among the three compared techniques: colorectal-first, liver-first and the combined approach.

Additional factor that should be taken into account is the localisation of the primary colorec- tal cancer. It was noted that the right-sided colorectal cancer with liver metastases was associated with significantly shorter mean overall survival than the left-sided tumour (44.1 vs 55.3 months). ${ }^{12}$ It seems however that one of the main predictive factors remains the tumour biology and presence of KRAS mutations ${ }^{13}$ - the tumour cells from the right-sided colorectal tumours had significantly more mutated-type KRAS than the left-sided colorectal tumours (48.8\% vs $28.8 \%$, respectively). ${ }^{12}$

\section{Conclusion}

It can be concluded that metastatic surgery for colorectal liver metastases and anatomic resections have almost the same results and are both irreplaceable methods in the treatment of colorectal liver metastases.

\section{Acknowledgements}

None.

\section{Conflict of interest}

None.

\section{References}

1. Morris EJ, Forman D, Thomas JD. Surgical management and outcomes of colorectal cancer liver metastases. Br J Surg 2010;97:1110-8.

2. Poston G. The argument for liver resection on colorectal liver metastases. Hepatogastronterology 2001;48(38):345-6.

3. Scheele J. Anatomical and atypical liver resections. Chirurg 2001;72(2):113-24.

4. Kim KH, Lee SG. Usefulness of Kelly clamp crushing technique during hepatic resection. HBP (Oxford) 2008;10(4):281-4.

5. Ikeda M, Hasegawa K, Sano K, Imamura H, Beck Y, Sugawara Y, et al. The vessel sealing system (LigaSure) in hepatic resection: a randomized controlled trial. Ann Surg 2009;250(2):199-203.

6. Fong Y, Fortner J, Sun RL, Clinical score for predicting recurrence after hepatic resection for metastatic colorectal cancer, analysis of 1001 consecutive cases. Ann Surg 1999;230:309-21.

7. De Matteo RP, Palese C, Jarnagin WR,Sun RL, Blumgart LH, Fong Y. Anatomic segmental hepatic resection in superior to wedge resection as an oncologic operation for colorectal liver metastases J Gastrointest Surg 2000;4(2):178-84.

8. Chakedis J, Squires MH, Beal EW, Hughes T, Lewis H,

Paredes A, et al. Update on current problems in colorectal liver metastasis. Curr Probl Surg 2017;54:554-602.

9. Allard MA, Adam R, Giuliante F, Lapointe R, Hubert C, Ijzermans JNM, et al. Long-term outcomes of patients with 10 or more colorectal liver metastases. Br J Cancer 2017;117:604-11.

10. Lam VW, Laurence JM, Pang T, Johnston E, Hollands MJ, Pleass HC, et al. A systematic review of a liver-first approach in patients with colorectal cancer and synchronous colorectal liver metastases. HPB (Oxford) 2014;16(2):101-8.

11. Kelly ME, Spolverato G, Lê GN, Mavros MN, Doyle F, Pawlik TM, et al. Synchronous colorectal liver metastasis: a network meta-analysis review comparing classical, combined, and liver-first surgical strategies. J Surg Oncol 2015;111:341-51.

12. Sasaki K, Andreatos N, Margonis GA, He J, Weiss M, Johnston $\mathrm{F}$, et al. The prognostic implications of primary colorectal tumor location on recurrence and overall survival in patients undergoing resection for colorectal liver metastasis. J Surg Oncol 2016;114:803-809.

13. Jones RP, Brudvik KW, Franklin JM, Poston GJ. Precision surgery for colorectal liver metastases: Opportunities and challenges of omics-based decision making. Eur J Surg Oncol 2017;43:875-83. 